\title{
Crecimiento y producción de fruta en cultivares de fresa(Fragaria sp.) afectados por encharcamiento
}

\section{Growth and yield of strawberry cultivars (Fragaria sp.) affected by flooding}

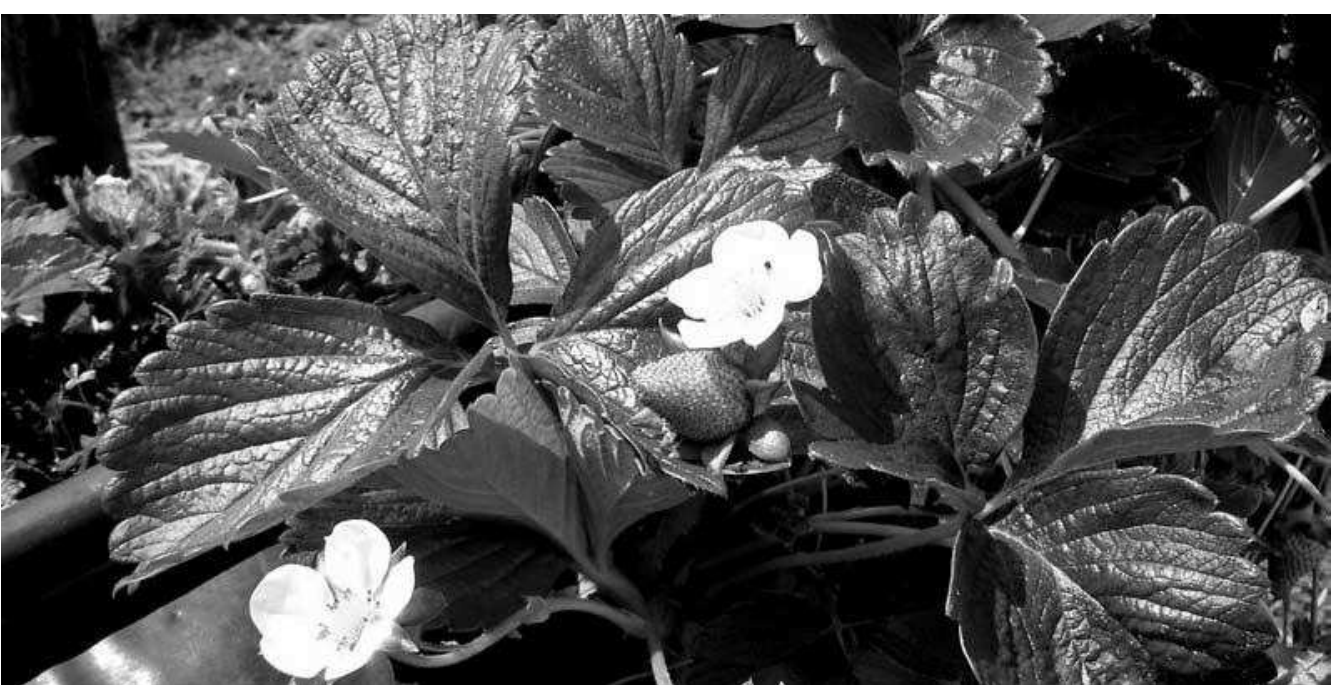

FÁNOR CASIERRA-POSADA ${ }^{1}$

YUBER A. VARGAS ${ }^{2}$

Planta de fresa cultivada en tubulares horizontales en Cómbita (Boyacá).

Foto: F. Casierra-Posada

\section{RESUMEN}

En general, el exceso de agua tiene un impacto negativo sobre el crecimiento y supervivencia de la mayoría de las plantas terrestres, en especial, cuando el encharcamiento ocurre durante la estación de crecimiento. En un experimento en materas, en invernadero en Tunja/Colombia, se determinó, la producción y distribución de materia seca, el peso específico de las hojas, la relación raíz / parte aérea, el total de fruta cosechada, el área foliar necrótica y normal, el índice de cosecha y el pH del suelo luego del encharcamiento, en tres cultivares de fresa: Chandler, Camarosa y Sweet Charlie. Las plantas se desarrollaron en suelo encharcado y sin encharcar (testigo). Como consecuencia del exceso de agua, el pH del suelo, el peso específico y el área necrótica de las hojas y la relación raíz / parte aérea, se incrementaron; mientras que la fruta cosechada, la producción total de materia seca y el área foliar total se redujeron. El encharcamiento también modificó la distribución de materia seca en los cultivares evaluados siendo el cultivar Chandler el más afectado por el encharcamiento en comparación con los demás cultivares. En general, las plantas de fresa mostraron un comportamiento muy pobre cuando fueron expuestas a condiciones de encharcamiento.

Profesor Asociado, Facultad de Ciencias Agropecuarias, Grupo Ecofisiología Vegetal, Universidad Pedagógica y Tecnológica de Colombia (UPTC), Tunja. fcasierra@tunja.uptc.edu.co

2 Ingeniero Agrónomo, Facultad de Ciencias Agropecuarias, Universidad Pedagógica y Tecnológica de Colombia (UPTC), Tunja.yavaf2077@yahoo.com 
Palabras clave adicionales: Estrés, pH del suelo, distribución de materia seca, relación raíz / parte aérea, índice de cosecha, hipoxia.

\section{ABSTRACT}

In general, the excess of water has a negative impact on growth and survival of most terrestrial plants, especially when flooding occurs during the growing season. In a pot experiment, the dry matter production and partitioning, specific leaf weight, root to shoot ratio, total harvested fruit, normal and necrotic leaf area, plant harvest index and $\mathrm{pH}$ of soil after flooding were measured in three strawberry cultivars. Plants were grown on a flooded and a non-flooded soil (control). The tested cultivars were Chandler, Camarosa and Sweet Charlie. This work was carried out in a greenhouse in Tunja, Colombia. As a consequence of flooding, the pH of soil, specific leaf weight, necrotic leaf area and root/shoot ratio increased, whereas the harvested fruit, total dry matter production and total leaf area were reduced. The dry matter partitioning pattern of the tested cultivars was modified by flooding too. Chandler cultivar was more affected by flooding than the rest of tested cultivars, although, strawberry plants showed in general poor behavior when were exposed to flooding conditions.

Additional key words: Stress, soil pH, dry matter, partitioning, root/shoot ratio, plant harvest index, hypoxia.
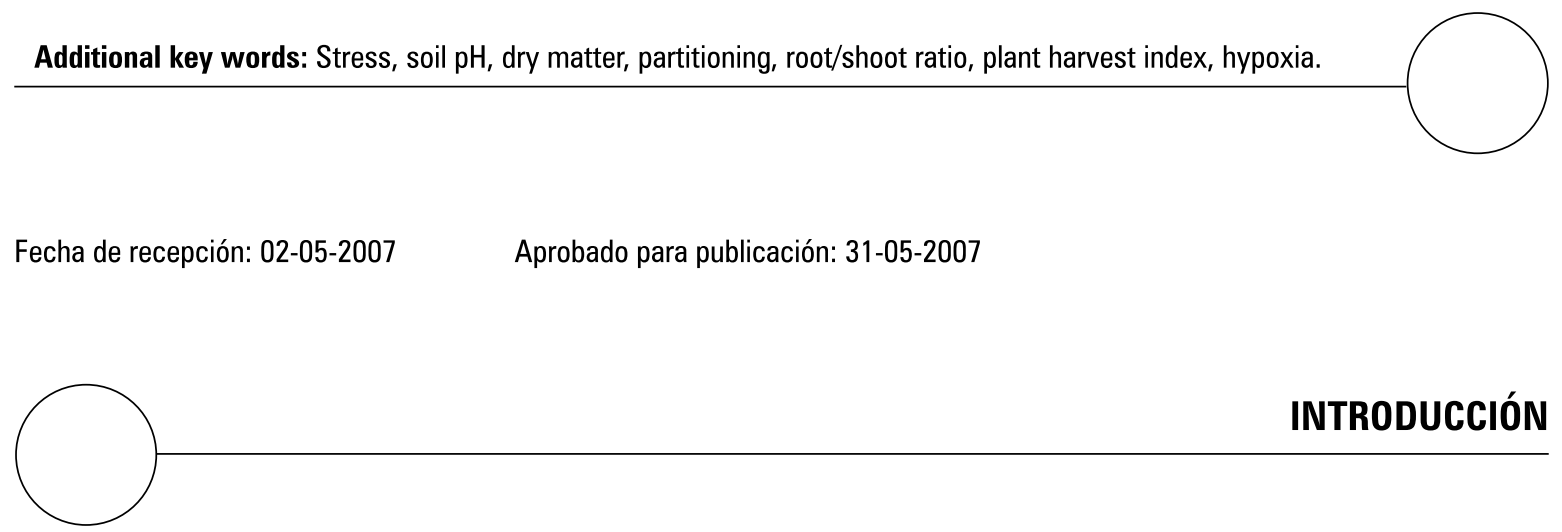

El área cultivada en fresas a nivel nacional alcanzó 702 ha en 2003, de las cuales $6,4 \%$ se encontraban en Boyacá, con un rendimiento de 17,2 tha ${ }^{-1}$. En Cundinamarca se cultivó el $64,2 \%$ del área nacional en ese año, con un rendimiento que alcanzó 37,2 tha ${ }^{-1}$ (Asohofrucol, 2003). La enorme brecha en cuanto al rendimiento en estos departamentos se debe, entre otros, al bajo nivel de tecnificación de este sistema de producción en Boyacá (Casierra-Posada y García, 2005). Dentro del sistema de producción de fresa en Colombia se involucra el uso de coberturas plásticas, que sirven para proteger los frutos de las pudriciones e impiden el crecimiento de arvenses, pero además, la cobertura plástica limita la evaporación del agua del suelo en épocas de alta precipitación, proporcionando así condiciones de baja disponibilidad de oxígeno a las raíces de las plantas.

Debido a que la mayoría de los representantes del género Fragaria son muy sensibles a las condiciones de estrés y a que sus frutos tienen alto valor comercial, se han desarrollado muchas investigaciones para evaluar el comportamiento de las plantas cultivadas bajo diferentes factores causantes de estrés, como presencia de metales pesados (Treder y Cieslinski, 2005; Casierra-Posada y Poveda, 2005), sequía (Pomper y Breen, 1997; McDonald y Archbold, 1998), temperaturas bajas (Nestby y Bjorgum, 1999; Rajashekar et al., 
1999; Nestby et al., 2001; Lindeen et al., 2002; Houde et al., 2004) y temperaturas altas (Gulen y Eris, 2004; 2004a; Ledesma y Sugiyama, 2005), a pesar de lo cual, es poco lo que se conoce en cuanto al comportamiento de plantas de fresa bajo hipoxia.

En cuanto al estrés causado por la baja disponibilidad de oxígeno en el sustrato, se debe mencionar que el oxígeno biatómico $\left(\mathrm{O}_{2}\right)$ es un requisito determinante en la producción eficiente de ATP a través de la fosforilación oxidativa en organismos aerobios. En eucariotes, el oxígeno es el receptor final en la cadena transportadora de electrones en la mitocondria. Por tanto, un agotamiento de éste tiene consecuencias rápidas y significativas en la fisiología celular. Esta condición altera la expresión genética, el consumo de energía, el metabolismo celular, y por ende, el crecimiento y desarrollo del organismo en cuestión se ven seriamente afectados. Las células vegetales afrontan con frecuencia niveles limitados del oxígeno en el sustrato, debido a cambios en el ambiente externo o altos índices del metabolismo celular (Geigenberger, 2003; Gibbs y Greenway, 2003; Greenway y Gibbs, 2003; Bailey-Serres y Chang, 2005).

Las condiciones naturales en que se desarrollan los vegetales, tales como inundaciones, exceso de precipitación, compactación del suelo y actividad de los microorganismos, pueden tener como consecuencia, una disminución en la disponibilidad de oxígeno. Durante la imbibición y germinación de las semillas, la producción de microsporas o el desarrollo de la fruta, la disponibilidad de oxígeno para la producción energética puede llegar a ser limitado. Esta condición puede deberse también a la restricción en la difusión de oxígeno en los tejidos internos o a los altos índices de metabolismo celular, como en células meristemáticas en división (Larcher, 2001; Bailey-Serres y Chang, 2005).

Las células de los organismos aerobios han desarrollado respuestas adaptativas tendientes a compensar la crisis energética generada por la privación del oxígeno. Las respuestas a nivel celular en plantas completas varían e incluyen alteraciones en el metabolismo y desarrollo, que en algunos casos confiere tolerancia a largo plazo. Se han hecho avances en la comprensión del papel de la activación o de factores que reducen la represión, transcripción y alteraciones en la expresión genética regulada por el oxígeno en algunos procariotes y eucariotes modelo. Los procesos que determinan estas respuestas incluyen sensores múltiples directos o indirectos y rutas de transducción de los mensajeros que actúan de manera independiente o recíproca. Los mecanismos de detección directa pueden implicar proteínas o compuestos que unen o reaccionan con el oxígeno. Perturbaciones en homeostasis celular, tales como niveles de energía alterados, estados rédox o niveles de calcio, pueden ser la base para detección de mecanismos indirectos. Paradójicamente, las respuestas eucariotes a la reducción del oxígeno parecen implicar la formación de especies reactivas de oxígeno (ROS) incluyendo el anión superóxido $\left(\mathrm{O}_{2}{ }^{-}\right)$, peróxido de hidrógeno $\left(\mathrm{H}_{2} \mathrm{O}_{2}\right)$ y óxido nítrico (NO) (Blokhina, 2000; Bailey-Serres y Chang, 2005).

Entre las adaptaciones estructurales frente al fenómeno de baja disponibilidad de oxígeno en el suelo, se encuentra la formación de aerénquima en tallos y raíces de plantas acuáticas y en aquellas tolerantes a situaciones de encharcamiento, lo que permite la oxigenación a larga distancia de los tejidos sometidos a hip oxia. La formación de tejido interconectado, lleno de gases, tiene lugar mediante dos rutas. En el primer caso, sucede la separación de las células durante el desarrollo y muerte programada de las células, lo cual sucede frecuentemente, incluso en plantas que crecen bajo condiciones normales (Drew, 1997). En el segundo caso, está implicada la participación del etileno (Jackson, 1985), el cual, en bajas concentraciones en el aire $\left(0,1-1,0 \mu \mathrm{L} \cdot \mathrm{L}^{-1}\right)$ promueve la muerte normal de las células, pero en raíces de plantas expuestas a hipoxia, se han encontrado concentraciones altas tanto de la hormona como de su precursor (He et al., 1994). 
El objetivo de este trabajo fue la determinación del comportamiento del crecimiento y la producción de fruta de tres cultivares de fresa expuestas a condiciones de encharcamiento, comparadas con plantas testigo, a las cuales se suministró riego dos veces por semana.

\section{MATERIALES Y MÉTODOS}

El ensayo se realizó bajo invernadero de la Universidad Pedagógica y Tecnológica de Colombia en Tunja, con temperatura promedio de $15,8^{\circ} \mathrm{C}$ y humedad relativa promedio de de $72 \%$. Se tomaron estolones seleccionados de plantas de fresa, de los cultivares Chandler, Camarosa y Sweet Charlie, los cuales se mantuvieron en cuarto frío $\left(4^{\circ} \mathrm{C}\right)$ durante tres semanas. Posteriormente, los estolones se sembraron en materas con capacidad para $5 \mathrm{~kg}$.

Para un normal desarrollo del experimento, a todas las plantas se les realizaron las labores y cuidados propios del cultivo durante cinco semanas. Seguidamente, de cada cultivar se tomaron diez plantas y se mantuvieron a capacidad de campo. A las diez plantas restantes por cultivar se les realizó saturación hídrica, para la cual, cada matera se forró con una bolsa plástica y se adicionó agua que saturara el suelo hasta la superficie. Las plantas se mantuvieron en el invernadero hasta que empezaron a presentar los síntomas de estrés, el primer cultivar en ser cosechado fue Camarosa a los 70 días después de la siembra, seguido de Chandler a los 81 días después de la siembra, y por ultimo, Sweet Charlie a los 94 días después de la siembra. Así, las plantas se colectaron cuando los síntomas del estrés por inundación se hicieron más evidentes para cada uno de los cultivares.

Como variables dependientes se tomaron: el peso seco de los tejidos, por secado de las muestras en una estufa a $105^{\circ} \mathrm{C}$, hasta peso constante; el peso específico de las hojas como el cociente en- tre el peso seco y el área foliar; la relación raíz / parte aérea, como la razón entre el peso seco de la raíz y los órganos aéreos; el índice de fruta cosechada, como el resultado de dividir el peso seco de la fruta cosechada entre el peso seco total de la planta; el área foliar se determinó con un analizador LI-COR@ 3000A (LI-COR, USA).

El experimento consistió en un ensayo bifactorial, con diseño completamente al azar, con diez replicaciones, tomando una planta como unidad experimental. La información se analizó mediante una tabla ANAVA y la prueba de separación de promedios de Tukey $(P<0,01)$ con el programa SPSS versión 11.5.

\section{RESULTADOS Y DISCUSIÓN}

El peso seco total alcanzado por las plantas durante el ensayo y el peso específico de las hojas, se vieron seriamente afectados por el encharcamiento, alcanzando diferencias altamente significativas $(P<0,01)$, pero no se presentó diferencia estadística entre cultivares ni en la interacción cultivar * condición. Sin embargo, en la variable relación raíz / parte aérea se presentó diferencia altamente significativa $(\boldsymbol{P}<0,01)$, para el factor cultivar y para la interacción de los factores cultivar * condición (tabla 1).

Aunque se reporta que comúnmente sucede incremento en la relación raíz / parte aérea, como consecuencia de la disminución del crecimiento de las raíces en plantas expuestas al encharcamiento (Kozlowski, 1997), en el presente experimento sucedió lo contrario. El incremento en la relación raíz / parte aérea en las plantas encharcadas estuvo relacionado con la disminución del crecimiento de los órganos aéreos y con la emisión de raíces adventicias en la zona cercana al cuello de la raíz. Es claro que la cantidad de oxígeno disuelto en el agua es mayor en la parte superior del suelo encharcado, por tanto, las plantas sometidas a encharcamiento desa- 
Tabla 1. Variables de acumulación de peso seco en tres cultivares de fresa (Fragaria sp.) sometidos a estrés por encharcamiento.

\begin{tabular}{|l|l|c|c|c|}
\hline \multicolumn{1}{|c|}{ Cultivar } & \multicolumn{1}{|c|}{ Condición } & $\begin{array}{r}\text { Peso seco total por planta } \\
\text { (g) }\end{array}$ & $\begin{array}{c}\text { Peso específico de las hojas } \\
\left(\mathbf{m g} \cdot \mathbf{c m}^{-2} \mathbf{~}\right.\end{array}$ & Relación raíz / parte aérea \\
\hline \multirow{2}{*}{ Chandler } & Normal & 9,30 & 5,68 & 0,48 \\
\cline { 2 - 5 } & Encharcado & 4,25 & 7,56 & 0,60 \\
\hline \multirow{2}{*}{ Camarosa } & Normal & 8,44 & 5,63 & 1,09 \\
\cline { 2 - 5 } & Encharcado & 4,56 & 7,65 & 1,87 \\
\hline \multirow{2}{*}{ Sweet Charlie } & Normal & 10,12 & 6,12 & 1,69 \\
\cline { 2 - 5 } & Encharcado & 5,36 & 7,23 & 1,27 \\
\hline
\end{tabular}

rrollan raíces adventicias cerca del cuello de la raíz, para así suplir la carencia de oxígeno en los horizontes inferiores del perfil del suelo. Las raíces adventicias desarrolladas están en contacto con el aire y pueden absorber $\mathrm{O}_{2}$; es así, como plantas sensibles al encharcamiento, como es el caso de las plantas de fresa, pueden producir estas raíces, pero no les permite sobrevivir así por mucho tiempo, dado que estas raíces son poco eficientes. La producción de raíces adventicias originadas en el periciclo, como consecuencia del encharcamiento es un fenómeno frecuente y también se ha reportado en plantas de Glycine max (Thomas et al., 2005).

A pesar de que se ha reportado la reducción del peso específico de las hojas en plantas de Brachiaria spp., como respuesta al encharcamiento (Dias-Filho y Carvalho, 2000), en el presente ensayo se encontró un incremento en el valor de esta variable. El incremento en el peso específico de las hojas en plantas de fresa expuestas al encharcamiento, pudo ser un efecto de la acumulación de almidón y fructanos en las hojas como consecuencia de la reducción en la translocación de azucares de las hojas a las raíces. Esto, como efecto de la falta de demanda de los órganos vertedero debida al crecimiento disminuido a causa del encharcamiento, dado que el crecimiento de la planta en términos de producción total de materia seca se reduce como consecuencia de la hipoxia causada por el encharcamiento (Hsu et al., 1999; Mustroph y Albrecht, 2003).
En lo relacionado con la producción total de fruta, se encontró diferencia altamente significativa $(P<0,01)$, tanto para los factores cultivar y condición, así como para la interacción de ambos. A pesar de que el cultivar más productor fue Chandler, también fue el más afectado por el encharcamiento, el cual redujo $82,5 \%$ la cantidad de fruta cosechada en relación con las plantas mantenidas bajo condiciones normales. El encharcamiento en los cultivares Camarosa y Sweet Charlie redujo su producción de fruta en términos de 31,2 y $19,7 \%$ respectivamente (tabla 2 ). El número de frutos cosechados por planta presentó diferencia altamente significativa $(P<0,01)$ para los factores cultivar y condición; y significativa $(P<0,05)$ para la interacción de ambos factores. El cultivar Chandler produjo el mayor número de frutos seguido de Camarosa y Sweet Charlie; a pesar de esto, el encharcamiento redujo en 59,2 y $60,0 \%$ el número de frutos de los cultivares Chandler y Camarosa, respectivamente, en comparación con las plantas control, mientras Sweet Charlie no fue afectado (tabla 2). El peso fresco por fruto también se redujo con el encharcamiento; fue así como los frutos del cultivar Chandler registraron mayor peso, seguidos de los de Sweet Charlie y Camarosa, respectivamente; sin embargo en plantas encharcadas de los cultivares Chandler y Camarosa se redujo en 60,9 y 3,0\% el peso fresco por fruto, mientras que en plantas encharcadas del cultivar Sweet Charlie el peso fresco de los frutos se incrementó 7,9\% (tabla 2). El índice de fruta cosechada mostró diferencia altamente sig- 
nificativa $(P<0,01)$ para el factor cultivar, y significativa $(P<0,05)$ para la interacción condición * cultivar, pero no hubo diferencia para el factor condición. El encharcamiento redujo el valor de este índice $48 \%$ en el cultivar Chandler, pero lo incrementó 25 y 150\% en los cultivares Camarosa y Sweet Charlie respectivamente (tabla 2).

Se reporta que las condiciones de hipoxia en el suelo inhiben la inducción floral, el cuajado y el crecimiento de frutos en plantas no tolerantes; también induce caída de flores y frutos. La dimensión en la alteración del crecimiento reproductivo es un factor altamente dependiente de la especie y de la prolongación de la exposición a las condiciones de hipoxia (Kozlowski, 1997). En plantas de Vaccinium ashei expuestas a encharcamiento se reduce entre 61 y $77 \%$ la cantidad de yemas florales, en comparación con plantas mantenidas en condiciones normales. Por el contrario, en plantas de Syzygium samaragense es común inducir la floración mediante el encharcamiento (Lin y Lin, 1992). El encharcamiento incrementa ligeramente el cuajado de frutos en Averrhoa carambola (Joyner y Schaffer, 1989), mientras que en Vaccinium macrocarpa y $V$. ashei lo reduce (Bergman, 1943; Crane y Davies, 1985; 1985a; 1989). Se ha encontrado que con frecuencia, el encharcamiento reduce el tamaño de los frutos, altera su apariencia y modifica su composición química (Crane y Davies, 1989). En Vaccinium macrocarpon (Bergman, 1943) se redujo el tamaño de los frutos; mientras que en $V$. corymbosum, además de la reducción en el tamaño, se redujo también el porcentaje de sólidos solubles totales (Abbott y Gough, 1987; 1987a).

La acumulación porcentual de materia seca en las raíces fue afectada sólo por el factor cultivar y por la interacción cultivar * condición en donde se encontraron diferencias altamente significativas $(P<0,01)$. El efecto del encharcamiento se manifestó con un incremento de 15,9 y $18,4 \%$ en el porcentaje de materia seca acumulada en las raíces en los cultivares Chandler y Camarosa, respectivamente; pero en el cultivar Sweet Charlie el porcentaje se redujo $14,2 \%$ (fig. 1 ).

En cuanto a la acumulación de materia seca en la corona, se encontraron diferencias altamente significativas $(P<0,01)$ para los factores cultivar y condición, y significativas $(\boldsymbol{P}<0,05)$ para la interacción de los dos factores. La condición de encharcamiento incrementó el contenido de materia seca en todas los cultivares evaluados, en proporciones de 50,8, 7,9 y 30,6\% para Chandler, Camarosa y Sweet Charlie, respectivamente. En cuanto a la cantidad de materia seca encontrada en las hojas, hubo diferencia significativa $(P<0,05)$ para el factor condición y altamente significativa $(P<0,01)$ para la interacción condición * cultivar. Para el factor cultivar no hubo diferencia estadísticamente significativa. El encharcamiento redujo 0,3 y 41,8\% la acumulación de materia seca en las hojas de los cultivares Chandler y Camarosa, pero en el cultivar Sweet Charlie se

Tabla 2. Variables de producción en tres cultivares de fresa (Fragaria sp.) sometidas a estrés por encharcamiento.

\begin{tabular}{|c|c|c|c|c|c|}
\hline Cultivar & Condición & $\begin{array}{l}\text { Producción total de } \\
\text { fruta }\end{array}$ & $\begin{array}{c}\text { Número de frutos } \\
\text { por planta }\end{array}$ & Peso fresco por fruto & $\begin{array}{c}\text { Índice de fruta } \\
\text { cosechada }\end{array}$ \\
\hline & & $(g)$ & & (g) & \\
\hline \multirow{2}{*}{ Chandler } & Normal & 23,31 & 5,4 & 4,17 & 0,25 \\
\hline & Encharcado & 4,13 & 2,2 & 1,61 & 0,13 \\
\hline \multirow{2}{*}{ Camarosa } & Normal & 3,50 & 2,5 & 0,97 & 0,04 \\
\hline & Encharcado & 2,19 & 1,0 & 0,94 & 0,05 \\
\hline \multirow{2}{*}{ Sweet Charlie } & Normal & 2,39 & 0,5 & 1,63 & 0,02 \\
\hline & Encharcado & 1,92 & 0,5 & 1,76 & 0,05 \\
\hline
\end{tabular}




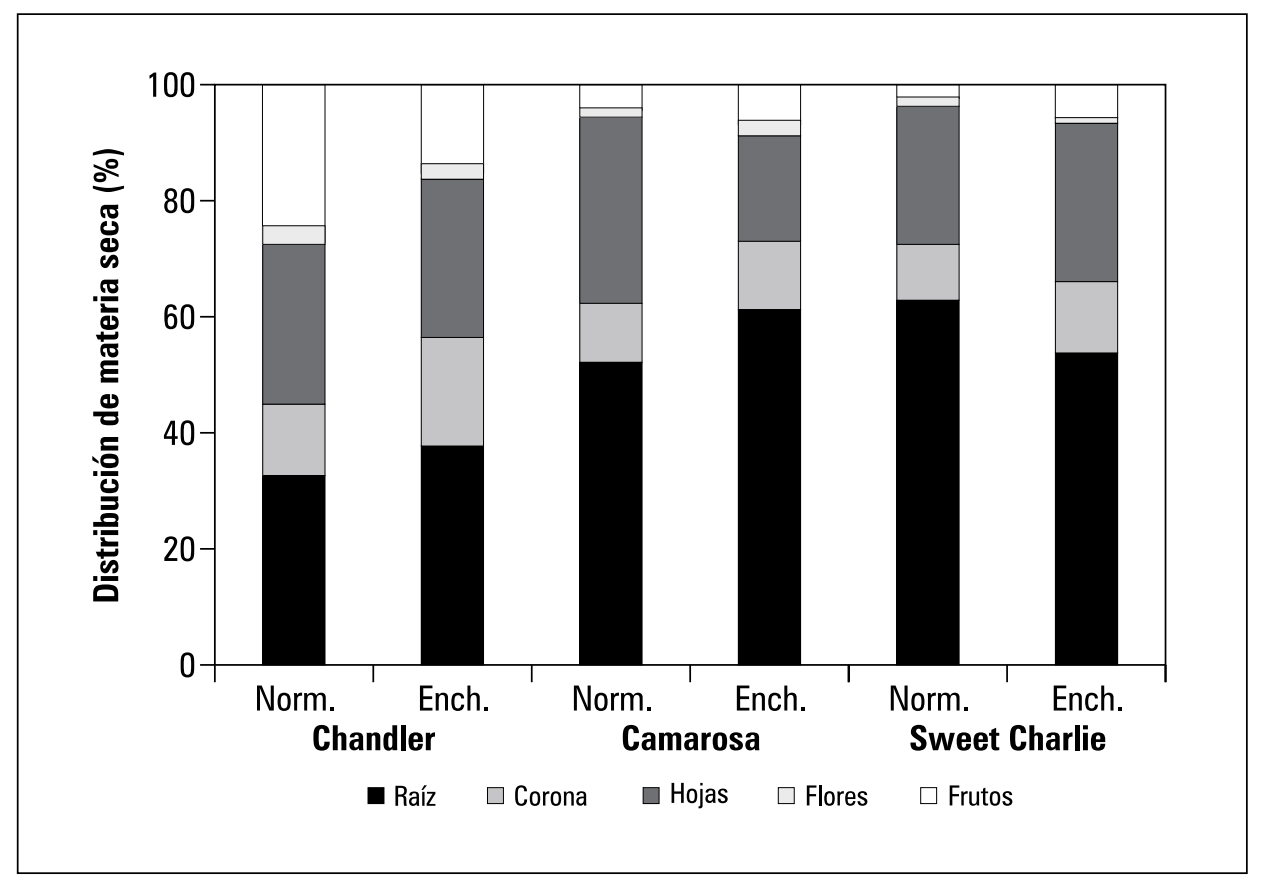

Figura 1. Distribución porcentual de fitomasa en tres cultivares de fresa (Fragaria sp.) sometidas a estrés por encharcamiento.

incrementó 15,6\%. El porcentaje de materia seca acumulada en las flores de las plantas evaluadas fue afectado por el factor cultivar $(P<0,01)$ y por la interacción de los factores condición * culti$\operatorname{var}(P<0,05)$, pero no por el factor condición. Los cultivares Chandler y Camarosa acumularon 5,5 y $177 \%$ más materia seca en las flores bajo condiciones de encharcamiento, mientras que esta condición redujo 16,6\% la materia seca en flores en el cultivar Sweet Charlie, en comparación con las plantas mantenidas en condiciones normales de humedad en el suelo. Se encontró diferencia altamente significativa $(P<0,01)$ en la acumulación de materia seca en frutos, para los factores cultivar y significativa $(\boldsymbol{P}<0,05)$ para la interacción cultivar * condición. El encharcamiento redujo esta variable en proporciones de 45,0 y $10,7 \%$ en los cultivares Chandler y Sweet Charlie, pero la acumulación de materia seca en frutos se incrementó $20,8 \%$ en Camarosa como consecuencia del encharcamiento, en relación con las plantas control.
Como consecuencia de la hipoxia y de que muchas de las raíces de plantas encharcadas mueren, se producen raíces adventicias en las porciones de tallo sumergidas. Estas raíces son, usualmente, más pesadas y presentan una mayor cantidad de espacios intercelulares que las raíces desarrolladas en suelos aireados (Hook et al., 1971), lo cual incrementó el peso seco de las raíces de plantas encharcadas. Por otro lado, las modificaciones en los patrones de acumulación de materia seca en los diferentes órganos se puede explicar mediante la alteración en la tasa fotosintética, dado que en plantas de fresa expuestas a encharcamiento, se produce un rápido cierre de los estomas, a pesar de que por algún tiempo, dependiente de la tolerancia del cultivar, la turgencia se puede conservar manteniendo la presión radicular y el gradiente electroquímico y de iones, asumiendo que los canales de agua permanecen funcionales, dado que la actividad de estos canales está relacionada con el transporte apoplástico de agua (Blanke y Cooke, 2006). 
Las plantas encharcadas alcanzaron sólo $36,8 \%$ del área foliar total de las plantas mantenidas bajo condiciones normales de humedad. Al respecto se encontró diferencia altamente significativa $(P<0,01)$; sin embargo, en cuanto a la interacción condición * cultivar, se encontró diferencia estadísticamente significativa $(P<0,05)$. En este caso, el cultivar Sweet Charlie presentó menor área foliar en comparación con los cultivares restantes, pero de igual manera, fue menos afectado por el encharcamiento (fig. 2). El encharcamiento redujo el área foliar en proporciones de $47,1,65,7$ y $74,4 \%$, respectivamente, para los cultivares Sweet Charlie, Chandler y Camarosa.

Sólo las plantas sometidas a encharcamiento presentaron áreas necróticas en las hojas. Por tanto, esta variable fue fuertemente afectada por el encharcamiento y se encontró diferencia altamente significativa $(P<0,01)$ para el factor condición, y significativa $(P<0,05)$ para el factor cultivar y para la interacción condición * cultivar (fig. 3).

El encharcamiento afecta negativamente el crecimiento de la parte aérea en muchas especies vegetales, mediante la inhibición de la formación de nuevas hojas, así como de la expansión foliary de crecimiento de internodos. También causa se- nescencia prematura y abscisión de las hojas (Kozlowski, 1984; Kozlowski et al., 1991; Kozlowski y Pallardy, 1996). La expansión de las hojas se inhibe debido a la reducción de la extensibilidad de las paredes celulares, la cual es un factor determinante para el crecimiento (Smit et al., 1989).

El valor de $\mathrm{pH}$ del suelo fue afectado por los factores condición y cultivar, y en ambos casos se encontró diferencia altamente significativa $(P<0,01)$. No se encontró diferencia para la interacción de ambos factores. De hecho, en todos los cultivares probados, se encontró un incremento en los valores de pH del suelo en que crecieron las plantas, cuando éstas se sometieron a encharcamiento (fig. 4). En condiciones de encharcamiento, el pH del suelo se incrementó más en el cultivar Camarosa, seguido por Sweet Charlie y por último, Chandler registró el menor incremento de $\mathrm{pH}$.

En suelos encharcados se acumulan grandes cantidades de compuestos potencialmente tóxicos como sulfuros, $\mathrm{CO}_{2}$, así como hierro y manganeso solubles (Kozlowski, 1997); otros compuestos como el etanol, acetaldehídos y compuestos cianogénicos son producidos por las raíces (Fulton y Ericsson, 1964; Rowe y Catlin, 1971; Ponnamperuma, 1984). Como productos del metabolismo

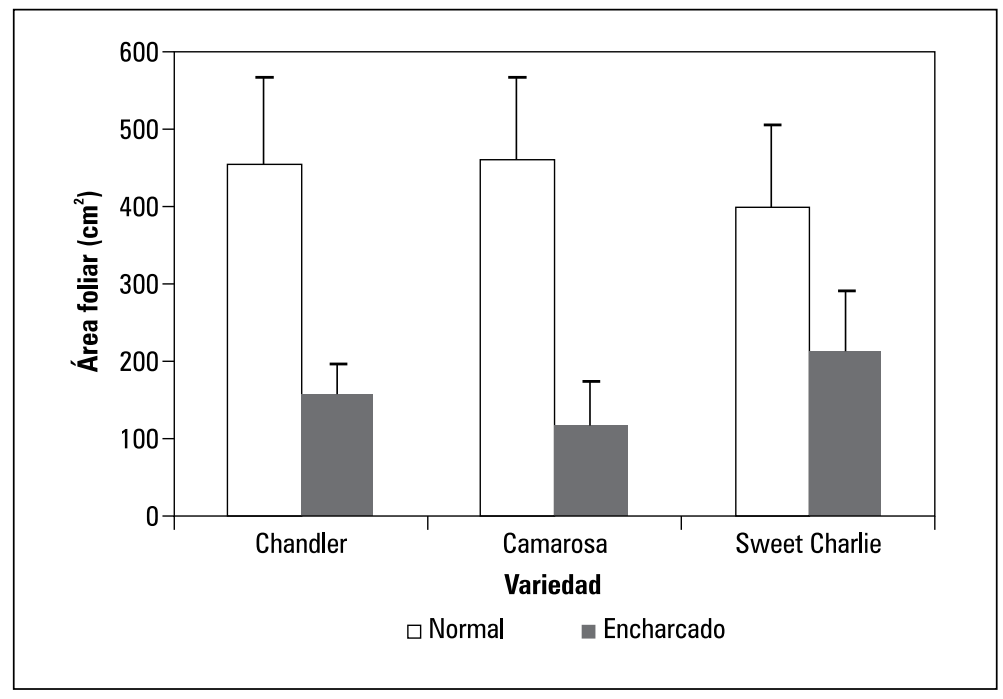

Figura 2. Área foliar por planta en tres cultivares de fresa (Fragaria sp.) sometidos a estrés por encharcamiento. 


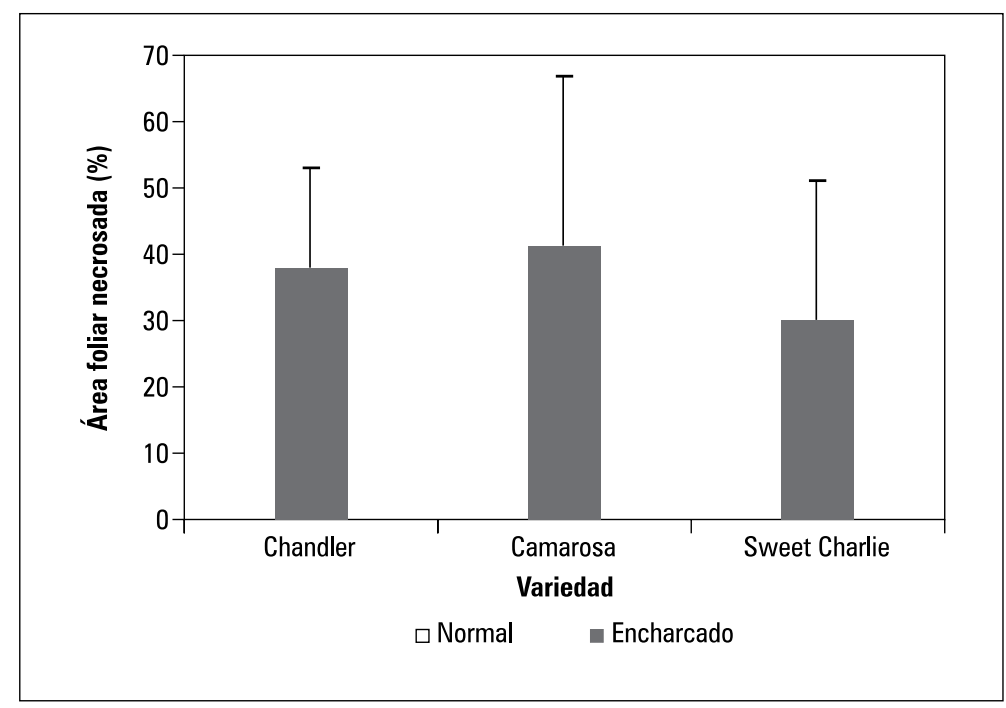

Figura 3. Área foliar necrosada en tres cultivares de fresa (Fragaria sp.) como consecuencia del estrés por encharcamiento.

anaeróbico de los microorganismos, se produce metano, etano, propileno, ácidos grasos, ácidos hidroxicarboxílicos, ácidos decarboxílicos, ácidos insaturados, aldehídos, cetonas, diaminas y compuestos heterocíclicos (Kozlowski, 1997). Estas reacciones en suelos inundados, así como la reducción de óxidos mangánicos e hidróxidos férricos permite la liberación de iones $\mathrm{OH}^{-}$, los cuales incrementan los valores de $\mathrm{pH}$ del suelo (León y Arregocés, 1985).

En términos generales, las alteraciones anatómicas, del crecimiento y del metabolismo como consecuencia de la hipoxia causada por el encharcamiento, reportada y discutida en el presente trabajo tienen sus fundamentos en los desordenes hormonales y en la restricción en la disponibilidad de ATP y de agua. Si la hipoxia se presenta durante un periodo muy prolongado, las plantas adquieren características típicas de déficit hídrico, como sucedió en los cultivares de fresa evaluados, dado que el encharcamiento fue permanente hasta el final del ensayo. El cultivar que evidenció en primer lugar, los síntomas de la hipoxia fue Camarosa, por lo que las plantas tuvieron que ser tomadas para análisis a los 70 días después de siembra, luego Chandler a los 81 días y por último, Sweet Charlie a los 94 días. La sintomatología de deshidratación de las plantas se debe a que bajo condiciones de hipoxia, la planta es incapaz de absorber el agua, porque se disminuye el transporte activo de iones necesario para que el agua se difunda por las raíces, y sin este transporte activo, para el que se necesita ATP, no hay absorción de agua, se cierran los estomas y la planta se deshidrata. La absorción de iones y agua se hace por un transporte activo que requiere ATP, cuya producción es muy limitada como consecuencia de la hipoxia, la cual inhibe el ciclo del ácido cítrico, induciendo una respiración anaeróbica en la que además de limitarse la producción de ATP, se producen metabolitos tóxicos (Brändle, 1996; Taiz y Zeiger, 2000; Larcher, 2001). Por el contrario, buenas condiciones de aireación en el sustrato en el que se desarrollan las plantas de fresa, favorecen el incremento del área foliar, el desarrollo de raíces y la producción y calidad de frutos (Sahin et al., 2005)

En cuanto a los cambios en el metabolismo del etileno, la anaerobiosis favorece el paso de SAM (S-Adenilato-Metionina) a ACC (Ácido aminociclo- 


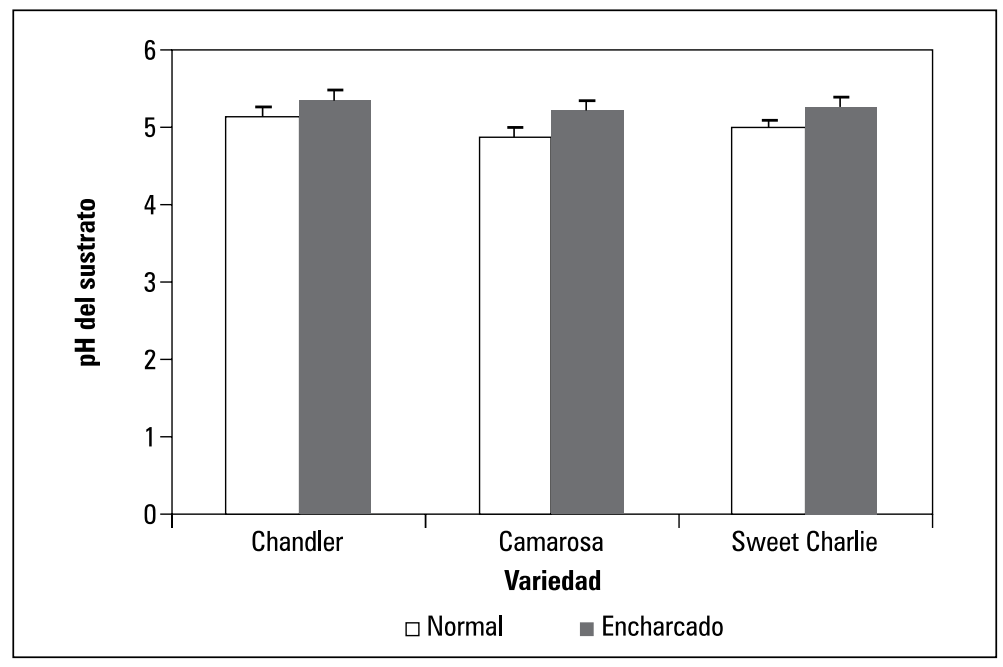

Figura 4. Valor de pH del suelo de tres cultivares de fresa (Fragaria sp.) sometidos a estrés por encharcamiento.

propano-1-carboxílico), pero para pasar de ACC a etileno se necesita $\mathrm{O}_{2}$. En las raíces hay producción de ACC que se trasloca a la parte aérea y cuando asciende por el xilema encuentra condiciones aeróbicas, así, el ACC se transforma en etileno, el cual induce la triple respuesta en plantas sensibles a la inundación. El incremento en el contenido de etileno hace también aumentar el contenido de auxinas en la parte aérea, provoca el cierre de estomas, así como la disminución de la fotosíntesis debido al cierre estomático y a que las plantas epinásticas sufren la acumulación de sustancias tóxicas que de igual manera afectan la fotosíntesis (Brändle, 1996; Taiz y Zeiger, 2000).

El exceso de agua en el sustrato tiene como consecuencia, la hipoxia, un tipo de estrés secundario, la cual es perjudicial para las plantas terrestres. El agua en exceso no es tóxica, por lo que no constituye un estrés primario, pero puede provocar un descenso de la concentración de $\mathrm{O}_{2}$ en los espacios aéreos del suelo y de los tejidos vegetales; así, la hipoxia representa un tipo de estrés secundario, dado que cuando el suelo está saturado de agua, el aire de los poros del suelo es desplazado por ésta y el $\mathrm{O}_{2}$ disuelto es rápidamente absorbido por microorganismos y plantas para satisfacer sus demandas, pero la disponibilidad de oxígeno es insuficiente para este efecto, lo cual causa los desequilibrios metabólicos presentados y discutidos a lo largo del presente texto.

\section{AGRADECIMIENTOS}

Este estudio fue desarrollado con el apoyo de la Dirección de Investigaciones (DIN) de la Universidad Pedagógica y Tecnológica de Colombia, Tunja, en el marco del plan de trabajo del grupo de investigación Ecofisiología Vegetal, adscrito al programa de Ingeniería Agronómica de la Facultad de Ciencias Agropecuarias. 
Abbott, J.D. y R.E. Gough. 1987. Reproductive response of the highbush blueberry to root-zone flooding. HortScience 22, 40-42.

Abbott, J.D. y R.E. Gough. 1987a. Prolonged flooding effects on anatomy of highbush blueberry. HortScience 22, 622-625.

Asohofrucol. 2003. Fresa. En: http://www.frutasyhortalizas.com.co/portal/Business/product_view.php; consulta: mayo 2007.

Bailey-Serres, J. y R. Chang. 2005. Sensing and signalling in response to oxygen deprivation in plants and other organisms. Ann. Bot. 96, 507-518.

Bergman, H.F. 1943. The relationship of ice and snow cover on winter-flooded cranberry bogs to vine injury from oxygen deficiency. En: Franklin, H.J.; H.F. Bergman y N.E. Stevens (eds.). Weather in cranberry culture. Mass. Agric. Exp. Stn. Bull., Amherst, MA. pp. 1-24.

Blanke, M. y D.T. Cooke. 2006. Water channels in strawberry, and their role in the plant's response to water stress. Acta Hort. 708, 65-68.

Blokhina, O. 2000. Anoxia and oxidative stress: Lipid peroxidation, antioxidant status and mitochondrial functions in plants. Tesis doctoral. Faculty of Science, University of Helsinki. 79 p.

Brändle, R. 1996. Überflutung und Sauerstoffmangel. En: Brunold, Ch.; A., Rüegsegger y R. Brändle (eds.). Streß bei Pflanzen. Editorial UTB für Wissenschaft, Stuttgart. pp. 133-148.

Crane, J.H. y F.S. Davies. 1985. Responses of rabbiteye blueberries to flooding. Proc. Fla. State Hortic. Soc. 98, 153-155.

Crane, J.H. y F.S. Davies. 1985a. Effects of flooding duration and season on rabbiteye blueberry growth and yield. HortScience 50, 529.

Crane, J.H. y F.S. Davies. 1989. Flooding responses of Vaccinium species. HortScience 24, 203-210.

Casierra-Posada, F. y N. García. 2005. Crecimiento y distribución de materia seca en cultivares de fresa (Fragaria sp.) bajo estrés salino. Agron. Colomb. 23(1), 83-89.
Casierra-Posada, F. y J. Poveda. 2005. La toxicidad por exceso de Mn y Zn disminuye la producción de materia seca, los pigmentos foliares y la calidad del fruto en fresa (Fragaria $s p$. cv. Camarosa). Agron. Colomb. 23(2), 283-289.

Dias-Filho, M.B. y C.J.R.D. Carvalho. 2000. Physiological and morphological responses of Brachiaria spp. to flooding. Pesq. Agropec. Bras., Brasília 35(10), 19591966.

Drew, M.C. 1997. Oxygen deficiency and root metabolism: Injury and acclimation under hypoxia and anoxia. Annu. Rev. Plant Physiol. Plant Mol. Biol. 48, 223- 250 .

Fulton, J.M. y A.E. Erickson. 1964. Relation between soil aeration and ethyl alcohol accumulation in xylem exudate of tomatoes. Proc. Soil Sci. Soc. Am. 28, 610-614.

Geigenberger P. 2003. Response of plant metabolism to too little oxygen. Curr. Opin. Plant Biol. 6, 247256.

Gibbs, J. y H. Greenway. 2003. Mechanisms of anoxia tolerance in plants. I. Growth, survival and anaerobic catabolism. Funct. Plant Biol. 30, 1-37.

Greenway, H. y J. Gibbs. 2003. Mechanisms of anoxia tolerance in plants. II. Energy requirements for maintenance and energy distribution to essential processes. Funct. Plant Biol. 30, 999-1036.

Gulen, H. y A. Eris. 2004. Some physiological changes in strawberry (Fragaria x Ananassa 'Camarosa') plants under heat stress. J. Hortic. Sci. Biotech. 78(6), 894-898.

Gulen, H. y A. Eris. 2004a. Effect of heat stress on peroxidase activity and total protein content in strawberry plants. Plant Sci.166 (3), 739-744.

He, Ch.-J.; M.C. Drew y P.W. Morgan. 1994. Plant induction of enzymes associated with lysigenous aerenchyma formation in roots of Zea mays during hypoxia and nitrogen starvation. Plant Physiol. 105, 861-865.

Hook, D.D.; C.L. Brown y P.P. Kormanik. 1971. Inductive flood tolerance in swamp tupelo (Nyssa sylvatica var. biflora (Walt.) Sarg.). J. Exp. Bot. 22, 78-89. 
Houde, M.; S. Dallaire; D. N'Dong y F. Sarhan. 2004. Overexpression of the acidic dehydrin WCOR 410 improves freezing tolerance in transgenic strawberry leaves. Plant Biotechnol. J. 2(5), 381-387.

Hsu, Y.-M.; M.-J. Tseng y Ch.-H. Lin. 1999. The fluctuation of carbohydrates and nitrogen compounds in flooded wax-apple trees. Bot. Bull. Acad. Sin. 40,193-198.

Jackson, M.B. 1985. Ethylene and responses of plants to soil waterlogging and submergence. Annu. Rev. Plant Physiol. 36, 145-174.

Joyner, M.E.B. y B. Schaffer. 1989. Flooding tolerance of 'Golden Star' carambola trees. Proc. Fla. State Hortic. Soc. 102, 236-239.

Kozlowski, T.T. 1984. Responses of woody plants to flooding. En: Kozlowski, T.T. (ed.). Flooding and plant growth. Academic Press, Orlando, FL. pp. 129-163.

Kozlowski, T.T. 1997. Responses of woody plants to flooding and salinity. Tree Physiol. Monograph No. 1. 29 p. En: http://www.heronpublishing.com/tp/monograph/kozlowski.pdf; consulta: junio 2007.

Kozlowski, T.T.; P.J. Kramer y S.G. Pallardy. 1991. The physiological ecology of woody plants. Academic Press, San Diego, CA. 657 p.

Kozlowski, T.T. y S.G., Pallardy. 1996. Growth control in woody plants. Academic Press, San Diego. 641 p.

Larcher, W. 2001. Ökophysiologie der Pflanzen. Sexta edición. Editorial Eugen Ulmer, Stuttgart. pp. 324328.

Ledesma, N. y N. Sugiyama. 2005. Pollen Quality and Performance in Strawberry Plants Exposed to Hightemperature Stress. J. Amer. Soc. Hort. Sci. 130, 341-347.

León, L.A. y O. Arregocés. 1985. Química de los suelos inundados. En: Arroz: Investigación y producción. Tascón, E.E.; D. García (eds.). Guía de Estudio. CIAT, Cali. pp. 287-305.

Lin, C.H. y C.H. Lin. 1992. Physiological adaptation of waxapple to waterlogging. Plant Cell Environ. 15, 321-328.

Lindeen, L.; P., Palonen y T. Hytonen. 2002. Evaluation of three methods to assess winter hardiness of strawberry genotypes. J. Hortic. Sci. Biotech. 77(5), 580588.

McDonald, S.S. y D.D. Archbold. 1998. Membrane competence among and within Fragaria species varies in response to dehydration stress. J. Amer. Soc. Hort Sci. 123(5), 808-813.

Mustroph, A. y G. Albrecht. 2003. Tolerance of crop plants to oxygen deficiency stress: Fermentative activity and photosynthetic capacity of entire seedlings under hypoxia and anoxia. Physiol. Plant. 117, 508-520.

Nestby, R.; R. Bjorgum. 1999. Freeze injury to strawberry plants as evaluated by crown tissue browning, regrowth and yield parameters. Sci. Hort. 81(3), 321329.

Nestby, R.; R. Bjorgum; A. Nes; T. Wikdahl y B. Hageberg. 2001. Reactions of strawberry plants to longterm freezing and alternate freezing and thawing. J. Hortic. Sci. Biotech. 76(3), 280-285.

Ponnamperuma, F.N. 1984. Effects of flooding on soils. En: Flooding and plant growth. Kozlowski, T.T. (ed.). Academic Press, Orlando, FL. pp. 9-45.

Pomper K.W. y P.J. Breen. 1997. Expansion and osmotic adjustment of strawberry fruit during water stress. J. Amer. Soc. Hort. Sci. 122(2), 183-189.

Rajashekar, C.B.; H. Zhou; K.B. Marcum y O. Prakash. 1999. Glycine betaine accumulation and induction of cold tolerance in strawberry (Fragaria $\mathrm{x}$ ananassa Duch.) plants. Plant Sci. 148(2), 175-183.

Rowe, R.N. y P.B. Catlin. 1971. Differential sensitivity to waterlogging and cyanogenesis by peach, apricot, and plum roots. J. Amer. Soc. Hort. Sci. 96, 305308.

Sahin, U.; S. Ors; S. Ercisli; O. Anapali y A. Esitken. 2005. Effect of pumice amendment on physical soil properties and strawberry plant growth. J. Central European Agr. 6(3), 361-365.

Smit, B.; M. Stachowiak y E. Van Volkenburgh. 1989. Cellular processes limiting leaf growth in plants under hypoxic root stress. J. Exp. Bot. 40, 89-94.

Taiz, L. y E. Zeiger. 2000. Physiologie der Pflanzen. Editorial Spectrum, Heidelberg. pp. 285-322.

Thomas, A.L.; S.M.C. Guerreiro y L. Sodek. 2005. Aerenchyma formation and recovery from hypoxia of the flooded root system of nodulated soybean. Ann. Bot. 96, 1191-1198.

Treder, W. y G. Cieslinski. 2005. Effect of silicon application on cadmium uptake and distribution in strawberry plants grown on contaminated soils. J. Plant Nutr. 28(6), 917- 929. 